\title{
Color Research in Urban Planning
}

\author{
YAN Jing \\ Gold Mantis School of Architecture ,Dushuhu Campus, Soochow University, No. 199, Ren'ai Road, \\ Su Zhou City, Jiang Su Province, PRC \\ yanemilia@126.com
}

\section{Keywords: Urban color; Urban planning; City vision}

Abstract: Urban color design is a concern of many cities in China in recent years. Since the 1980s, Chinese cities have generally lacked of aesthetic cultivation and attention to the urban color in the process of rapid development. The colors of various new materials and coatings, the random posting of urban advertisements and the construction of new urban buildings are painted in many cities with colorful "big faces". It makes the city lose its distinct personality and historical context. It also causes serious visual pollution and affects the physical and mental health of urban residents. Under such a background, the problem of urban color began to attract the attention of many urban decision makers. From the perspective of aesthetics and practical space, this paper makes a preliminary discussion on the significance and application principles of urban color planning.

Urban color refers to the color of various visual things in the outer space of the city. It is a broad and comprehensive concept, which is divided into artificial decoration color and natural color. Its research objects include architecture, roads, signs, advertisements, clothing, green land, rivers and other urban human and natural landscape colors.[1] Urban color is an important component of the human living environment and the first element of urban environmental visual form. It is closely related to people's living environment, living quality and future development.

International academic circles began to pay attention to the problem of "urban color" in the 1970s. Since the 17th century Turin, Italy began planning to the implementation of the construction of urban environment color .Since the 1970 s, Europe, Japan and other countries for the construction of urban color have achieved obvious results. Scientific and orderly urban color planning and construction resulted in many foreign cities with distinct personalities, harmony. Urban color planning and construction of these cities brought immeasurable intangible assets. "Let me see the face of your city, and I can tell you what kind of culture the city is pursuing," said the famous architect Sharinin. Every city brings people different feelings with its different colors, shapes and features.

In the choice of Paris city color, cheese color and dark gray color became the symbol color of Paris. This makes it clear that people are in Paris whenever they go to any corner of the city while they see the two colors. The primary form of wood, stone as the construction of the building materials makes Kyoto beautiful and pleasing, coupled with the traditional architectural style of the classic charm. Landscape of Kyoto achieved the rates with an example of perfect and unified in the three aspects of color, shape,

At present, China's urbanization is entering a rapid development stage, and a large number of buildings have sprung up. Because we are in the process of urban planning and construction for a 
long time, the lack of deep understanding of architectural and environmental colors still lags far behind the advanced countries, from theory research to practice application has a large gap. Over the past 20 years, since the reform and opening up, China's backward urban color design has formed a strong contrast with the rapid urban construction speed, which has seriously restricted the harmonious development of the city and the environment. The disorder of color in the urban public environment reveals the deficiency of China's urban color management at will. Although our country advertisement law does not have relevant regulation to chromatics, the common pursuit is a new era Urbanite.

According to the analysis of the status quo, two main factors affect on environmental color chaos. Firstly, it results from discordance between the appearance and color of buildings springing up around and the main color of the city style. Result in visual pollution problem in the history of architecture and environment, actually, no uniform criteria and supervision of the implementation of color in the field of the building of the city color confused, which forms a negative impact on urban image shaping. Although in the construction of the urban color, landscape color occupies the critical position, the development of the modern city cannot be ignored. Furthermore, the second reason that conduces the color chaos of environment is connected with urban advertising and urban psoriasis. Reviewing freely crisscross the city landscape, walking or driving between high and low buildings, a kind of interference is proposed to make it impossible to get rid of colorful that the other signs and advertising in the city. The city advertises severely impact on the urban color, and it is undeniable that modern and prosperous business depends largely on advertising. However, with the neglect of urban managers to the issues of advertising, signs, image, aesthetic, color and so on appearing in the process of economic development, most of the advertising color is simply chosen for stimulating eyes, which are more brilliant, good, and some of which are not designed aesthetic feeling. Those light boxes and colorful neon lights advertising are almost not distinct from "urban psoriasis" small advertising. As the color of the dress is a person's first impression, public signs in the city color represent the degree of civilization of a city, management level and the mental outlook of society as a whole. This situation is common in many Chinese cities, which damages the urban environment and color landscape seriously.

Urban color is a new research topic, and it is of great significance in protecting and developing urban and regional culture and constructing harmonious urban landscape. The appearance of a city is the most direct reflection of a region's economic development, quality of life and regional cultural traditions. As the concept of urban color has lagged behind for a long time, the formation of urban color landscape in China is basically autonomous and voluntary. Therefore, the study of urban color is of great significance in urban construction and environmental improvement, which will provide a scientific and theoretical basis for better urban planning, construction and management of the urban color landscape.

Marx once said: "the feeling of color is the most popular forms of" general aesthetic feeling. Paying attention to color will facilitate the color, can use color in the urban landscape, to create a feast for the eyes of audience and construct a vivid rich color environment. However, different colors give people different psychological feelings and psychological stimulation. White is cold. Red and orange make people feel warm. Blue is calming. Flower with color profusion makes a person feel happy. This is a kind of intense psychological reflection of natural colors on to human beings. In addition, color has rich symbolic meanings. Red represents enthusiasm and happiness. Green 
represents peace and ideals. Blue represents calmness, rationality, etc., which can give people a psychological hint. Thus the psychological effect of color varies. This effect should not be ignored while choosing the color. Color not only has its own characteristics, but also serves as a medium for the transmission of cultural information. It contains the connotation that people attach to it and represents the culture of cities and countries to a certain extent. Beijing's royal palace complex with red and yellow colors hidden in the thick woods is simple but elegant. Park-like courtyard dwellings are of bright color contrast, which constitutes the characteristics of the city. The coastal city of Qingdao is characterized by red tile roofs, beige walls, green trees, blue sky, blue sea and white waves. To the contrary, the natural colors of Suzhou are from white walls, gray tile roofs, slate roads and stone bridges. The ancient green trees and vivid reflection of water make up the scenery of the 'Jiangnan Water Village'. Generally speaking, the colors of northern cities are bright and colorful, while those of southern cities are light and elegant. Each city should try to make use of the urban characteristics inherited from history and culture, cherish these unique color characteristics, in order to construct their own unique urban appearance.

Urban color is an important factor in the composition of urban landscape, which deeply affects people's environmental feelings. The implementation and management of urban color landscape planning and design is the practical factor for the city to successfully accept a comfortable, pleasant and beautiful living environment. In the future, a prominent personality and vivid and rich living environment can be created with the assistance of reasonable application of the construction of urban landscape, the urban color planning, the design of the systematic, scientific and unified in the current urban planning. Based on the essence of color, in addition, the research Angle of Urban color planning and design ought to focus on human nature with the research object of considering the urban connotation generally. Actually, the color that occupies the dominant position to attract people's attention is mainly reflected by that of the city building. As the most prominent attractions the building is the main part in an urban landscape, building color accordingly became the leading role of urban color, and proper management of the color processing directly affects on the urban color beauty. Building colors include residential building color, commercial buildings, office buildings, entertainment color, color education, architecture and so on. Furthermore, the choice of the color reflects the specific building function, the perfect combination of color and function is a considerable factor in a successful architecture design. Besides, the selection of architectural colors is supposed to focus on the commonness, contrast, sequence and priority of colors to enhance the changes and features of architectural colors. For example, the eaves of Tibetan dwellings are the favorite color of the Tibetan people- sauce red, accompanying with milky white walls and black side decorations on doors and Windows. Last but not least, color of building roof is normally ignored in the consideration of urban color management, but it fills the blank for urban color in the bird's view, especially for those cities with rich beautify landscape, which avoids a single, dark gray urban landscape and enhances the attractiveness of the city.

In addition, as the role of the urban landscape corridor, each roads possesses the dynamic landscape sequence of moving different scenarios, and is also the channel to display the charm of the city. Suitable road color enhances the pedestrians' physical and mental health, especially for those walking on some commercial pedestrian street. With a color that coordinates to the street shop floor tile in the roadside buildings, a scenery line of color is presented towards pedestrians when they walk along this road. [2] Moreover, color management of highway is also very critical as scientific allocation of color provides good psychological impacts to drivers with the aim of reducing traffic 
accidents. Besides, underground street is also worthy of attention, according to the situation that reasonable and scientific color selection is considered to reduce the uncomfortable sense of the dark and cold underground environment. Furthermore, as the square is the node of urban space and gathering center of social life for urban residents, positive applications of colors in the square proposed to attract more people to stay here, and to create a public space for the city which can be recognized and accepted. [3] Such as New York subsided Rockefeller plaza, the deep red trees and marble metope make the former set of golden sculptures outstanding out of visual and fountain of white behind interval. When dining in the middle of the square with the color of the tent and the square formation of color space, this square is full of rhythm and strong spiritual appeal.

Environment sketch color, the color of auxiliary facilities, has the function of conveying information and creating nice material of urban color. Take the decorations on the western Europe streets as an example. It forms a beautiful landscape zone where telephone booths, shelters, lamps and so on are carefully designed and discretion with rich color and strong artistic quality, and are coupled with the colorful sculptures, fountains on those streets.[4] Although such items are not the main parts of urban landscape, improper treatment will not only damage the image of the city, but also cause obstacles to citizens' identification, which is not conducive to effective information transmission. For dangerous parts and signal devices, warning colors should be specified and color combinations are reasonable to be conspicuous to remind people. To summarize, it is critical to seek the unity of function and beauty in the color design of environmental sketch.

The urban construction in Beijing set the facade to adopt the compound color, which gives priority to the gray attune tune, which not only opposites to the atmosphere of previous monarchy, but also represents the grand momentum of this city as the political and cultural center. Furthermore, considering the local climate, compound grey taking compound grey is chosen as the main color of local urban buildings, with light color and gray acting as "light makeup". This kind of colorific collocation can reflect the city character of Chengdu, collect concurrently, also accord with the grade of the famous historical city photograph. And Hangzhou is also made up of cyan grey, grey green, green and so on, which have the "harmonious color" with Jiang Nan sentiment of ink.

Urban color is an important factor in the composition of urban landscape, which deeply affects people's feelings of environmental. The implementation and management of urban color landscape planning and design is the practical link to obtain a comfortable, pleasant and beautiful living environment. In the future,we should pay great attention to the construction of urban landscape, the urban color planning in the current urban planning and the design of the systematic, scientific, unified.We can create a prominent living environment.

\section{References}

[1]Sijin Yin.Urban color landscape planning and design[M].Nanjing: southeast university press, 2004;8-12.

[2]Symonds.Landscape design: site planning and design manual[M].Beijing: China building industry press,2000;34-36.

[3]Clare.Human nature places[M]Beijing: China building industry press, 2001:11- 13.

[4]Meng Gang, Li Lan.Urban park design[M].Shanghai: tongji university press,2003;58 - 60. 